\title{
ANALISIS RISIKO KESELAMATAN DAN KESEHATAN KERJA KEGIATAN BONGKAR MUAT PUPUK
}

\author{
Rian Muhamid, Willy Tambunan, Lina Dianati Fatimahhayati \\ Program Studi Teknik Industri, Fakultas Teknik, Universitas Mulawarman \\ Email: riyanmuhamdi@yahoo.com; wil_ly22@yahoo.com; linadianatif@gmail.com
}

\begin{abstract}
Abstrak - Sebuah perusahaan yang melayani jasa Pelayanan Bongkar Muat (PBM) yang meliputi kegiatan pembongkaran dan pemuatan barang yang dilakukan pada kawasan Pelabuhan Dermaga juga memiliki potensi kecelakaan kerja yang tinggi. Dari wawancara dengan petugas safety, kecelakaan yang terjadi masih sebatas kecelakaan ringan seperti iritasi mata akibat debu dan iritasi pada kaki akibat pupuk yang bocor dan mengenai tubuh pekerja. Berdasarkan sisi pekerja, potensi kecelakaan kerja bisa terjadi tertimpa pupuk, iritasi akibat pupuk yang bocor, gangguan pernafasan dari kondisi ruangan yang berbau kimia pupuk serta terjatuh dari truk. Penelitian ini bertujuan mengetahui kegiatan yang memiliki potensi kecelakaan kerja dan melakukan penilaian risiko yang terjadi dengan metode HIRARC. Objek penelitian adalah perusahaan yang bergerak dalam kegiatan bongkar muat yang beroperasi di Kalimantan Timur. Pengumpulan data dilakukan dengan cara observasi langsung dengan cara mengamati lokasi dan aktivitas pekerja. Selain itu dengan cara wawancara langsung dengan pihak Safety Officer (1 orang), Koordinator Lapangan (1 orang),Tally Man (1 orang), Rager Crane Kapal (1 orang) dan pekerja lapangan yang berjumlah 33 pekerja. Hasil penelitian diperoleh faktor-faktor risiko dari 8 kegiatan seperti menempatkan crane, menyiapkan peralatan bongkar muat, memasang sling dan hook ke hook crane, menyiapkan meja tally man di sisi dermaga, pekerja masuk ke dalam tongkang, mengarahkan truk pengangkut, pemuatan pupuk, mengarahkan truk untuk meninggalkan dermaga dan 14 potensi bahaya. Dari penilaian risiko diperoleh 3 sumber hazard yang bernilai ekstrim, 9 sumber hazard yang memiliki nilai risiko tinggi dan 2 sumber hazard yang memiliki nilai risiko sedang. Pengendalian risiko dapat dilakukan dengan memberikan pengarahan $K 3$, membuat prosedur kerja yang baik,serta penggunaan APD yang lengkap dalam melakukan kegiatan bongkar muat.
\end{abstract}

Kata kunci: HIRARC; Kecelakaan; Risiko

\begin{abstract}
A company that serves loading and unloading services which includes demolition and loading of goods carried out in the Pier Port area also has a high potential for workplace accidents. From interviews with safety officers, accidents that occur are still limited to minor accidents such as eye irritation due to dust and irritation to the feet due to fertilizer leaking and about the body of the worker. Based on the workers' side, the potential for workplace accidents can be overwritten by fertilizers, irritation due to leaky fertilizers, respiratory problems from chemical conditions that smell of fertilizers and fall from trucks. This study aims to determine the activities that have the potential for workplace accidents and carry out risk assessments that occur with the HIRARC method. The object of research is a company engaged in loading and unloading operations operating in East Kalimantan. Data collection is done by direct observation by observing the location and activities of workers. Also, by direct interview with the Safety Officer (1 person), Field Coordinator (1 person), Tally Man (1 person), Rager Crane Ship (1 person) and field workers totaling 33 workers. The results of the study obtained risk factors from 8 activities such as placing cranes, preparing loading and unloading equipment, installing slings and hooks to crane hooks, preparing tally man tables on the dockside, workers entering barges, directing transport trucks, fertilizer loading, heading vehicles to leave the dock and 14 potential hazards. From the risk assessment obtained three sources of extreme value hazard, nine sources of hazard that have high-risk values and two sources of hazards that have moderate risk values. Risk control can be done to providing K3 guidance, make good working procedures, and use complete PPE in carrying out loading and unloading activities.
\end{abstract}

Keywords: Accident; HIRARC; Risk 


\section{PENDAHULUAN}

Keselamatan dan Kesehatan Kerja (K3) merupakan suatu program yang dibuat sebagai upaya mencegah timbulnya kecelakaan akibat kerja dan penyakit akibat kerja. Tujuan program ini adalah untuk menciptakan tempat kerja yang nyaman dan sehat sehingga dapat menekan serendah mungkin risiko kecelakaan dan penyakit (Ramli, 2010). Peningkatan program K3 diharapkan berdampak pada penurunan angka kecelakaan kerja di perusahaan.

Kecelakaan kerja dapat terjadi karena kondisi unsafe action dan unsafe condition (Suma'mur, 2000). Unsafe action yaitu tindakan yang salah dalam bekerja dan tidak sesuai dengan yang telah ditentukan (human error), biasanya dipengaruhi oleh kondisi lingkungan kerja yang tidak baik atau kondisi peralatan kerja yang berbahaya (unsafe condition) (Supriyadi, Nalhadi, \& Rizaal, 2015). Unsafe condition dipengaruhi hal-hal seperti alat yang tidak layak pakai, alat pengaman yang tidak memenuhi standar.

Sebuah perusahaan yang melayani jasa Pelayanan Bongkar Muat (PBM) yang meliputi kegiatan pembongkaran dan pemuatan barang yang dilakukan pada kawasan Pelabuhan Dermaga juga memiliki potensi kecelakaan kerja yang tinggi. Dalam kegiatan pembongkaran dan pemuatan memiliki jenis sumber bahaya dan potensi bahaya yang kemungkinan terjadi seperti pada pekerjaan dalam mengarahkan kendaraan di area dermaga yang kemungkinan pekerja mengalami kecelakaan tertabrak oleh kendaraan serta melakukan pekerjaan di area tongkang kapal pada saat mengangkat pupuk ke dalam jaring pengangkut yang berpotensi bahaya tertimpa material serta kesalahan dalam mengangkat material tersebut. Walaupun menggunakan alat berat berupa crane darat dan kapal, namun hampir sebagian kegiatan bongkar muat tersebut masih dikerjakan secara manual oleh pekerja, sehingga menyebabkan risiko kecelakaan kerja seperti tergelincir, terhempas, dan tertimpa material.

Dari wawancara dengan petugas safety, kecelakaan yang terjadi masih sebatas kecelakaan ringan seperti iritasi mata akibat debu dan iritasi pada kaki akibat pupuk yang bocor dan mengenai tubuh pekerja. Beberapa faktor yang menimbulkan kecelakaan terjadi pada lokasi dermaga yang belum lengkap dengan ramburambu, faktor kondisi lantai kapal dan kondisi alat angkut. Berdasarkan sisi pekerja, potensi kecelakaan kerja bisa terjadi tertimpa pupuk, iritasi akibat pupuk yang bocor, gangguan pernafasan dari kondisi ruangan yang berbau kimia pupuk serta terjatuh dari truk. Pada salah satu bagian penggunaan kondisi APD yang tidak sesuai dengan kondisi pekerjaan membuat pekerja kesulitan bekerja jika memakai APD.

Hazard Identification and Risk Assessment Risk Control (HIRARC) merupakan salah satu metode yang banyak dilakukan pada kegiatan bongkar muat (Aryani, 2016; Prasetio, Aryani, \& Meikawati, 2016; Sanusi, Despriadi, \& Yusdinata, 2017). HIRARC terdiri dari serangkaian fase komprehensif untuk mengidentifikasi bahaya, penilaian risiko dan penentuan langkah-langkah pengendalian untuk pelaksanaan keselamatan dan kesehatan kerja (Saedi, Thambirajah, \& Pariatamby, 2014). Unsur penting dari penilaian risiko adalah identifikasi bahaya yang ada, mengevaluasi kemungkinan atau peluang terjadi kecelakaan kerja dan merekomendasikan kontrol yang relevan (Supriyadi \& Ramdan, 2017).

Penelitian ini bertujuan mengetahui kegiatan yang memiliki potensi kecelakaan kerja dan melakukan penilaian risiko yang terjadi. Nilai ini sebagai dasar pengambilan rekomendasi perbaikan untuk meminimalkan potensi kecelakaan kerja yang terjadi.

\section{METODE PENELITIAN}

Penelitian ini menggunakan tahapan HIRARC dalam proses identifikasi, penilaian dan kontrol dari risiko yang ada. Objek penelitian dilakukan pada perusahaan yang bergerak dalam kegiatan bongkar muat yang beroperasi di Kalimantan Timur. Pengumpulan data dilakukan dengan cara observasi langsung dengan cara mengamati lokasi dan aktivitas pekerja. Selain itu dengan cara wawancara langsung dengan pihak Safety Officer (1 orang), Koordinator Lapangan (1 orang), Tally Man (1 orang), Rager Crane Kapal (1 orang) dan pekerja lapangan yang berjumlah 33 pekerja.

Pengolahan data dilakukan dengan menggunakan Tahapan HIRARC. Langkah awal adalah mengidentifikasi urutan proses yang ada pada kegiatan bongkar muat. Setiap proses akan diidentifikasi potensi bahaya dengan cara mengamati segala kemungkinan penyimpangan yang mungkin terjadi.

Penilaian risiko terdiri dari serangkaian proses yang terkait dengan analisis risiko, penilaian besarnya risiko, penilaian apakah risiko dapat diterima atau tidak dapat diterima, dan menciptakan dan menilai opsi pengendalian risiko. Penilaian risiko memainkan peran penting dalam keputusan yang dibuat oleh organisasi dalam rangka menerapkan kebijakan keselamatan dan kesehatan secara rasional (Kyokai, 2009). Risiko mengukur kemungkinan dan keparahan dari kejadian kecelakaan mengukur besarnya dan memprioritaskan 
bahaya yang teridentifikasi. Salah satu alat penilaian risiko yang paling umum untuk mengevaluasi risiko adalah peringkat matriks risiko yang mencakup konsekuensi, kemungkinan dan keparahan sumbu, sehingga kombinasi parameter ini memberi kita perkiraan risiko atau peringkat risiko.

Risiko: Likelihood (L) x Severity (S)

Tabel 1. Kriteria Likelihood

\begin{tabular}{|c|c|c|c|}
\hline \multicolumn{4}{|c|}{ Likelihood } \\
\hline Level & Criteria & $\begin{array}{l}\text { Description } \\
\end{array}$ & \\
\hline 1. & Jarang terjadi & $\begin{array}{l}\text { Dapat dipikirkan tetapi tidak hanya saat } \\
\text { keadaan yang ekstrim }\end{array}$ & $\begin{array}{c}\text { Kurang dari } 1 \text { kali per } \\
10 \text { tahun }\end{array}$ \\
\hline 2. & Kemungkinan kecil & $\begin{array}{l}\text { Belum terjadi tetapi bisa muncul / terjadi } \\
\text { pada suatu waktu }\end{array}$ & $\begin{array}{l}\text { Terjadi } 1 \text { kali per } 10 \\
\text { tahun }\end{array}$ \\
\hline 3. & Mungkin & $\begin{array}{l}\text { Seharusnya terjadi dan mungkin telah } \\
\text { terjadi / muncul disini atau di tempat lain }\end{array}$ & $\begin{array}{l}1 \text { kali per } 5 \text { tahun } \\
\text { sampai } 1 \text { kali per } \\
\text { tahun }\end{array}$ \\
\hline 4 & $\begin{array}{l}\text { Kemungkinan } \\
\text { besar }\end{array}$ & $\begin{array}{l}\text { Dapat terjadi dengan mudah, mungkin } \\
\text { muncul dalam keadaan yang paling } \\
\text { banyak terjadi }\end{array}$ & $\begin{array}{l}\text { Lebih dari } 1 \text { kali per } \\
\text { tahun hingga } 1 \text { kali } \\
\text { perbulan }\end{array}$ \\
\hline 5. & Hampir pasti & $\begin{array}{c}\text { Sering terjadi, diharapkan muncul } \\
\text { dalam keadaan yang paling banyak } \\
\text { terjadi }\end{array}$ & $\begin{array}{l}\text { Lebih dari } 1 \text { kali per } \\
\text { bulan }\end{array}$ \\
\hline
\end{tabular}

Tabel 2. Kriteria Consequences / Severity

\begin{tabular}{|c|c|c|c|}
\hline \multicolumn{4}{|c|}{ Consequences/Severity } \\
\hline Level & Uraian & Keparahan Cidera & Hari Kerja \\
\hline 1. & Tidak signifikan & $\begin{array}{l}\text { Kejadian tidak menimbulkan kerugian } \\
\text { atau cedera pada manusia }\end{array}$ & $\begin{array}{l}\text { Tidak menyebabkan } \\
\text { kehilangan hari kerja }\end{array}$ \\
\hline 2. & Kecil & $\begin{array}{c}\text { Menimbulkan cedera ringan, kerugian } \\
\text { kecildan tidak menimbulkan dampak } \\
\text { serius terhadap kelangsungan bisnis }\end{array}$ & $\begin{array}{c}\text { Masih dapat bekerja } \\
\text { pada hari / shift yang } \\
\text { sama }\end{array}$ \\
\hline 3. & Sedang & $\begin{array}{l}\text { Cedera berat dan dirawat dirumah sakit, } \\
\text { tidak menimbulkan cacat tetap, kerugian } \\
\text { finansial sedang }\end{array}$ & $\begin{array}{l}\text { Kehilangan hari kerja } \\
\text { dibawah } 3 \text { hari }\end{array}$ \\
\hline 4. & Berat & $\begin{array}{c}\text { Menimbulkan cedera parah dan cacat } \\
\text { tetap dan kerugian finansial besar serta } \\
\text { menimbulkan dampak serius terhadap } \\
\text { kelangsungan usaha }\end{array}$ & $\begin{array}{c}\text { Kehilangan hari kerja } 3 \\
\text { hari atau lebih }\end{array}$ \\
\hline 5 & Bencana & $\begin{array}{c}\text { Mengakibatkan korban meninggal dan } \\
\text { kerugian parah bahkan dapat } \\
\text { menghentikan kegiatan usaha } \\
\text { selamanya }\end{array}$ & $\begin{array}{l}\text { Kehilangan hari kerja } \\
\text { selamanya }\end{array}$ \\
\hline
\end{tabular}




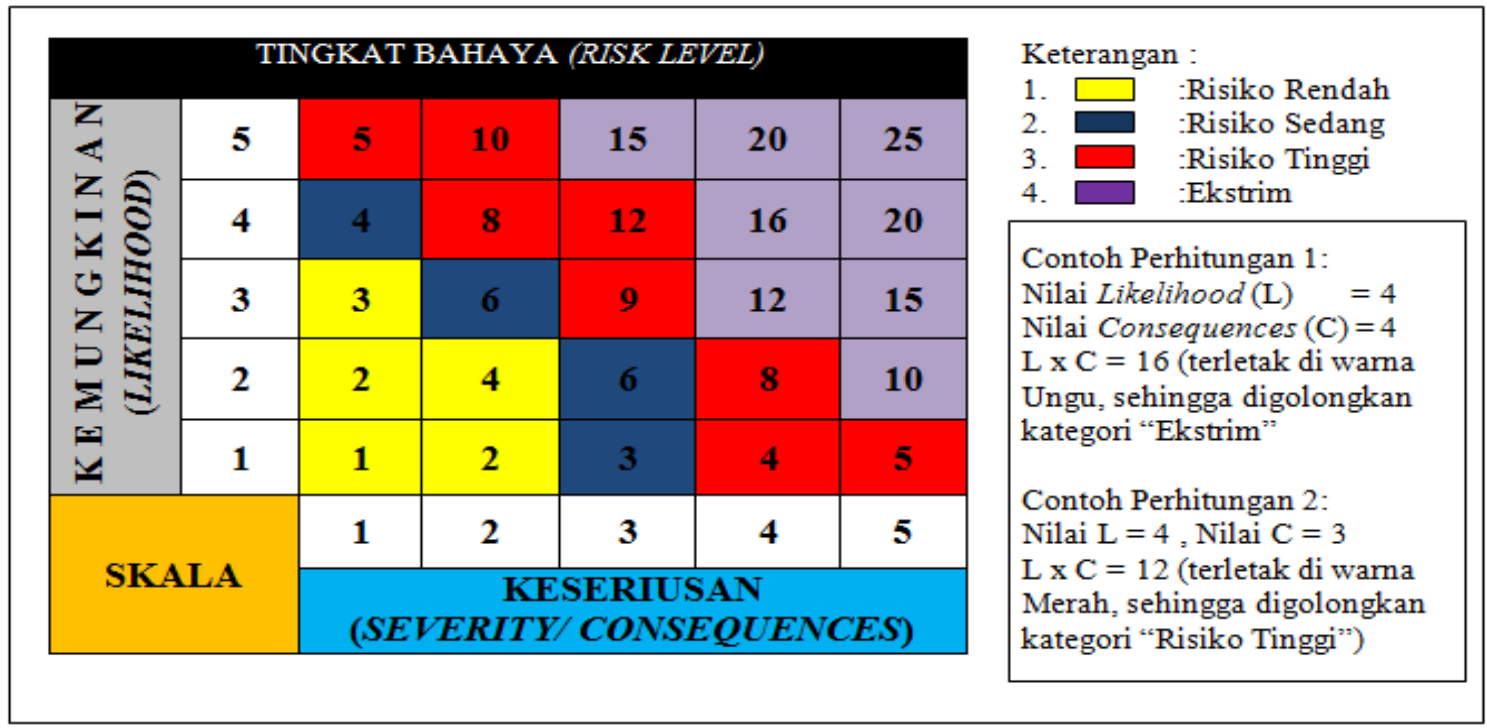

Gambar 1 Risk Matrik

\section{HASIL DAN PEMBAHASAN}

Pengolahan data berdasarkan urutan aktivitas kerja bongkar muat. Dari hasil observasi dan wawancara yang dilakukan terdapat sebanyak 8 temuan proses aktivitas pekerjaan sebagai berikut:

1. Menempatkan Crane

Dalam kegiatan ini sebelum melakukan aktivitas pekerjaan bongkar muat tally man mengarahkan operator crane untuk di tempatkan ke sisi dermaga.

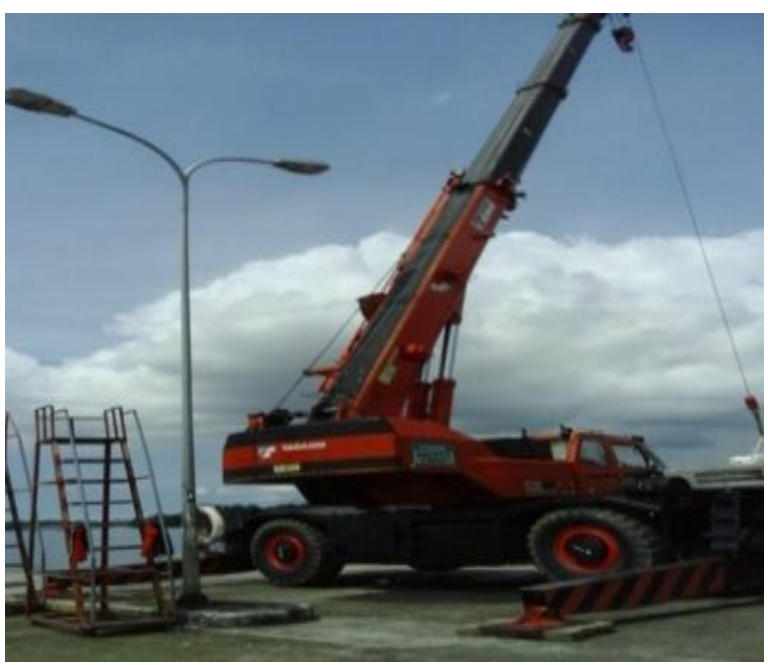

Gambar 2. Menempatkan Crane

2. Menyiapkan Peralatan Bongkar Muat

Tally man menyiapkan semua peralatan bongkar muat dari gudang menuju ke dermaga sebelum melakukan aktivitas pekerjaan.

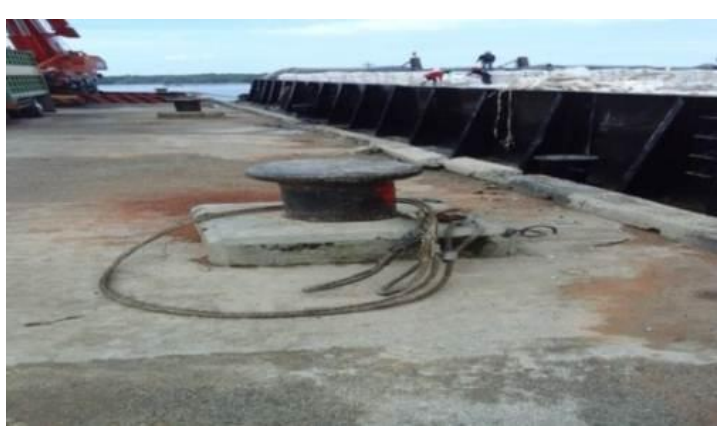

Gambar 3. Menyiapkan Peralatan Bongkar Muat

3. Memasang Sling dan Hook ke Hook crane Setelah crane dihidupkan selanjutnya menurunkan sling hook crane dan mengaitkan hook sling.

4. Menyiapkan meja tally man di sisi dermaga Tally man menyiapkan meja untuk melakukan pencatatan surat jalan truk dan mencatat jumlah muatan yang akan dimuat ke dalam truk pengangkut.

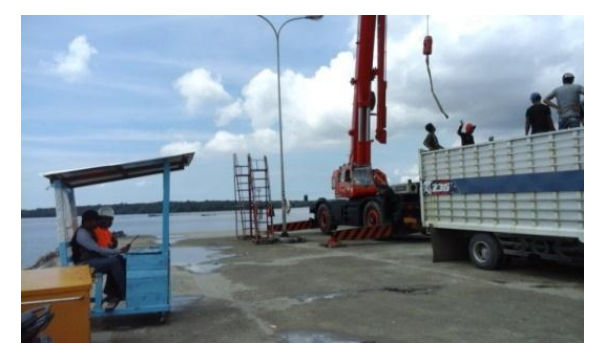

Gambar 4. Menyiapkan Meja Tally man 
5. Pekerja masuk ke dalam Tongkang

Setelah crane hidup dan peralatan sudah siap untuk melakukan aktivitas pekerja, selanjutnya pekerja masuk ke dalam tongkang untuk melakukan kegiatan mengangkat pupuk ke dalam jaring.

6. Mengarahkan Truk Pengangkut

Tally man mengarahkan truk ke sisi pemuatan yang sudah ditempatkan

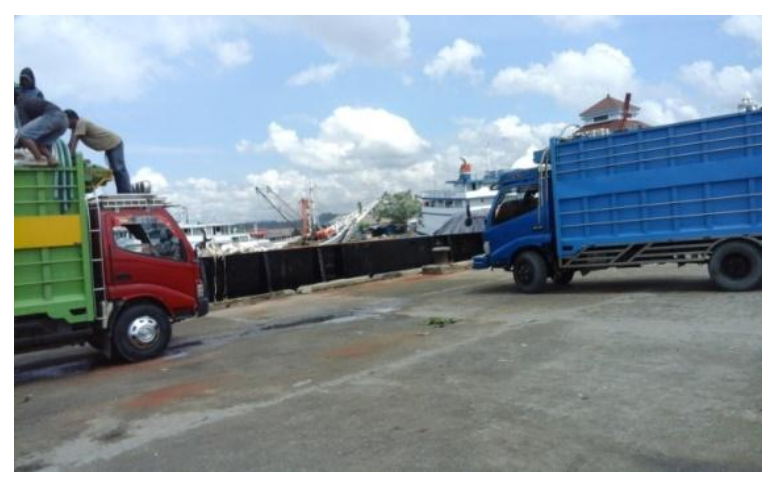

Gambar 5 Mengarahkan truk ke tempat pemuatan

7. Pemuatan pupuk

Setelah pekerja menyusun pupuk ke dalam jaring selanjutnya, jaring diangkat menggunakan crane menuju truk pengangkut dan diarahkan pekerja yang ada di dalam truk untuk menempatkan jaring ke dalam ruang bak truk

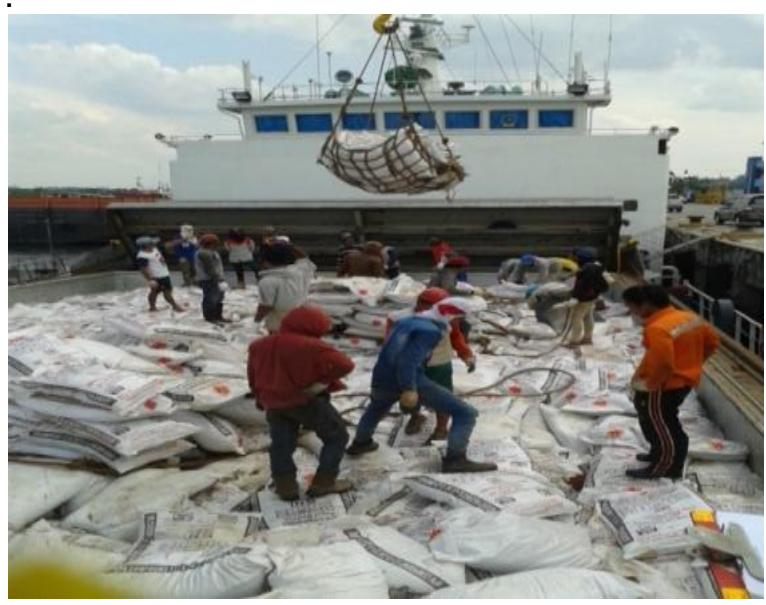

Gambar 6. Pemuatan Pupuk ke dalam Jaring

8. Mengarahkan truk untuk meninggalkan dermaga

Setelah muatan di dalam bak truk sudah memenuhi jumlah muatannya, selanjutnya truk meninggalkan dermaga dan mengarahkan truk selanjutnya untuk di muat pupuk.

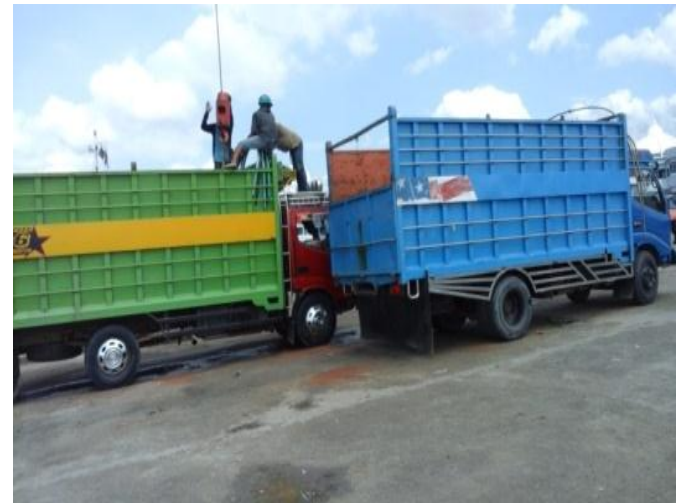

Gambar 7. Mengarahkan Truk Meninggalkan Dermaga

Proses identifikasi risiko merupakan tahapan identifikasi risiko yang mungkin terjadi dari setiap kegiatan yang sudah diidentifikasi. Potensi risiko yang terjadi pada kegiatan penempatan crane adalah kemungkinan tubuh terluka dan terjatuh ke laut dikarenakan sempitnya lokasi dermaga dan kurangnya fasilitas rambu-rambu dan safety dermaga yang memadai. Alat tools yang berat, sling, jaring dan hook yang berkarat pada kegiatan penyiapan peralatan bongkar muat menyebabkan kemungkinan kaki tertimpah alat angkut bila kejatuhan material.

Beban alat angkut sling dan hook yang berat pada kegiatan pemasangan menyebabkan kaki tertimpah alat angkut, luka memar pada tangan dan kaki. Tertabrak truk kendaraan merupakan risiko penempatan meja tally man yang tidak aman karena posisi meja terlalu di pinggir dermaga.

Potensi kecelakaan yang terjadi pada kegiatan pekerja masuk tongkang adalah tubuh tergelincir jatuh yang disebabkan tangga licin dan berkarat. Iritasi, luka memar akibat tersandung papan palet yang berserakan dan bag bocor.

Pada kegiatan mengarahkan truk pengangkut, potensi bahaya yang terjadi adalah tertabrak truk, iritasi pada mata, gangguan pernafasan dan pendengaran. Kegiatan pemuatan pupuk memiliki risiko sakit tulang punggung, luka memar pada tangan, tertimpah pupuk jika terjatuh dari jaring dan terjepit bak truk ketika hendak jaring di turunkan ke dalam bak truk. Tertabrak dan terlindas truk merupakan potensi risiko yang terjadi pada kegiatan yang melintas diare dermaga.

Penilaian potensi bahaya yang di identifikasi bahaya risiko melalui analisa dan evaluasi bahaya risiko yang dimaksudkan untuk menentukan besarnya risiko dengan mempertimbangkan kemungkinan terjadi dan besar akibat yang ditimbulkan. Penelitian risiko 
(risk assessment) mencakup dua tahap proses yaitu menganalisa resiko (risk analysis) dan mengevaluasi risiko (risk evaluation). Kedua tahap ini sangat penting karena akan menentukan langkah dan strategi pengendalian risiko.

Parameter yang digunakan untuk melakukan penilaian risiko adalah likelihood dan severity. Likelihood adalah probabilitas terjadinya kecelakaan kerja. Parameter pengukuran likelihood yang digunakan dalam penelitian ini adalah seberapa sering terjadinya kegiatan yang dapat memicu kecelakaan kerja. Risk rating menggambarkan seberapa besar dampak dari potensi bahaya yang diidentifikasi yang kemudian akan dilihat dengan bantuan tabel risk matrix. Hasil penilaian risiko diperoleh 2 kegiatan mempunyai risiko sedang, 9 kegiatan risiko tinggi dan 3 kegiatan yang memiliki risiko ekstrim (Tabel 3).

Tabel 3. Penilaian Risiko

\begin{tabular}{llllll}
\hline No & Hazard & RISK & & \\
\hline 1. & Area manuver crane & 2 & 4 & 8 & Tinggi \\
2. & Sling, jaring dan hook yang berkarat & 5 & 2 & 10 & Tinggi \\
3. & Alat tool yang berat & 4 & 2 & 8 & Tinggi \\
4. & Alat angkut sling dan hook yang berat & 5 & 2 & 10 & Tinggi \\
5. & Penempatan meja tally man yang tidak aman & 2 & 4 & 8 Tinggi \\
6. & Tangga Licin dan berkarat & 5 & 3 & 15 & Ekstrim \\
7. & Lantai tongkang berair dan papan palet berserakan & 5 & 2 & 10 & Tinggi \\
8. & Tally Man Mengarahkan Kendaraan ke posisi pemuatan & 2 & 3 & 6 Sedang \\
9. & Debu dan asap kendaraan & 5 & 2 & 10 & Tinggi \\
10. & Kebisingan dari bunyi kendaraan & 5 & 2 & 10 Tinggi \\
11. & Pekerja mengangkat manul ke dalam jaring & 5 & 3 & 15 Ekstrim \\
12. & Jaring di angkat oleh crane & 2 & 4 & 8 Tinggi \\
13. & Menurunkan jaring ke dalam bak truk & 4 & 4 & 16 Ekstrim \\
14 & Truk yang melintas diare dermaga & 2 & 3 & 6 Sedang \\
\hline
\end{tabular}

Perancangan rekomendasi atau usulan perbaikan dilakukan berdasarkan hazard (potensi bahaya) yang terjadi. Ini bertujuan agar semua permasalahan dari sumber bahaya yang ada didapatkan solusinya. Dengan adanya usulan perbaikan yang diberikan nanti perusahaan dapat mengurangi tingkat kecelakaan dan mencegah adanya kecelakaan yang serupa lagi dengan sebelumnya.

Kondisi manuver perlu menjadi perhatian khusus, dimana area manuver crane di dermaga yang lokasi maneuver terbatas sehingga berpotensi kecelakaan yang tidak terduga, maka memerlukan rekomendasi seperti menunjuk dan menempatkan seorang flag man pada area manuver crane untuk mengarahkan pergerakan crane dan memasang rambu-rambu lalu lintas. Rekomendasi yang diberikan dalam persiapan alat angkut adalah mengangkat alat angkut dengan hati-hati dengan memakai APD lengkap seperti sepatu safety, sarung tangan, dan helm safety, menempatkan alat angkut pada sisi dermaga, jaring yang selesai dipakai harus cepat dibersihkan sebelum mengering, memberikan pelumas ke hook dan sling sehingga mengurangi karat yang menempel dan mengelompokan jenis alat angkut pada tempatnya di dalam gudang.

Langkah pengurangan risiko kecelakaan pada kegiatan perbaikan pemasangan sling dan hook pada hook crane adalah menurunkan hook crane sejajar dengan sling dan mengaitkan hook sling ke hook crane menggunakan obeng ataupun tangan dengan cara berhati-hati. Perbaikan meja tempat tally man dapat dilakukan dengan menyiapkan tempat khusus untuk tally man dalam melakukan pencatatan surat jalan kendaraan angkut.

Rekomendasi yang diberikan khususnya dalam mengarahkan jaring berisi pupuk ke dalam truk pengangkut adalah proses menurunkan jaring pekerja tidak perlu berada di dalam truk, sebaiknya disediakan tangga khusus untuk melepaskan kaitan jaring dari hook crane. Kondisi dermaga menjadi salah satu faktor terpenting dalam kelangsungan operasi kegiatan bongkar muat, maka perlu adanya pemerhatian khusus mulai dari kondisi lantai dermaga, ramburambu lalu lintas di dermaga dan Safety pelabuhan. Hal ini terlihat pada kegiatan bongkar muat pupuk yang dimana kondisi lantai dermaga masih banyak kekurangan sehingga perlu adanya rekomendasi perbaikan dan tambahan berupa rambu-rambu, dan prosedur kegiatan bongkar muat.

Banyaknya material yang menumpuk di tengah tongkang yang tergenang air dan 
tumpukan palet yang berserserakan, sehingga mengganggu aktivitas kegiatan pekerja. Hal ini disebabkan pekerja hanya terfokus pada pekerjaan bongkar dan muat tanpa memikirkan kondisi lingkungan kerja yang berserakan sehingga perlu adanya penggeseran ke pinggir badan tongkang agar pekerja nyaman melakukan pekerjaan dan kurangnya pemantauan dari pihak mandor lapangan terhadap kondisi lingkungan kerja. Tidak adanya prosedur yang baik juga mempengaruhi terjadinya pelanggaran sehingga di lingkungan kerja yang dapat mengakibatkan potensi kecelakaan kerja yang diakibatkan oleh material yang tidak teratur dan baik dalam penataannya. Untuk mengatasi hal ini maka diberikan rekomendasi perbaikan yaitu pembuatan prosedur penataan dan pengaturan bahan baku ataupun material lainnya seperti bag robek, bag kosong, super bag, dan papan palet di susun dengan rapi sehingga dapat mengurangi risiko potensi kecelakaan yang dapat terjadi. Selain itu, pihak manajemen agar lebih mempertegas peraturan yang dibuat, sehingga proses kegiatan bongkar muat dapat berjalan dengan baik serta tingkat keselamatan kerja lebih tinggi.

Hal yang sangat diperhatikan terutama pekerja pada saat melakukan pengangkatan pupuk ke dalam jaring pengangkut, dimana kegiatan angkat mengangkat dilakukan secara manual, sehingga pekerja rentang mengalami sakit tulang belakang dan kejatuhan dari pupuk yang mengenai kaki. Sehingga rekomendasi perbaikan yang diberikan adalah melakukan teknik pengangkatan bersama-sama yang dilakukan oleh dua orang, guna meringankan beban yang diangkat dan mendekatkan jaring agar tidak terlalu jauh mengangkat.

Rekomendasi perbaikan yang diusulkan untuk menanggulangi potensi bahaya yang disebabkan oleh potensi bahaya (hazard) sikap pekerja yang tidak memenuhi standar dalam keselamatan kerja dan prosedur kerja yang baik adalah dengan membuat jadwal pelatihan K3 tentang penggunaan APD yang akan diselenggarakan oleh pihak manajemen. Bagi para pekerja yang yang tidak dapat menghadiri pelatihan akan dikenakan sanksi. Bentuk dari sanksi yang akan dijatuhkan sesuai dengan kesepakatan pihak perusahaan.Membuat worksheet dalam penggunaan APD di area kerja supaya para pekerja dapat langsung membaca apa saja potensi bahaya yang akan mereka alami apabila tidak menggunakan APD. Membuat visual display mengenai penggunaan Alat Pelindung Diri (APD) pada area kerja yang memiliki potensi-potensi kecelakaan kerja dan membuat Standard Operating Procedure (SOP) penggunaan Alat Pelindung Diri (APD). Visual display di pasang di beberapa tempat untuk memberikan himbauan kepada para pekerja agar selalu menggunakan APD dengan baik

\section{KESIMPULAN}

Dari hasil analisa yang telah dilakukan diperoleh hasil bahwa faktor-faktor risiko yang menyebabkan potensi bahaya kecelakaan kerja yang dapat terjadi pada area proses kegiatan bongkar muat Pupuk Nitrogen Fosfor Kalium (NPK) berasal 8 aktivitas kegiatan seperti menempatkan crane, menyiapkan peralatan bongkar muat, memasang sling dan hook ke hook crane, menyiapkan meja tally man di sisi dermaga, pekerja masuk ke dalam tongkang, mengarahkan truk pengangkut, pemuatan pupuk, mengarahkan truk untuk meninggalkan dermaga. Dari penilaian risiko diperoleh 3 sumber hazard yang bernilai ekstrim, 9 sumber hazard yang memiliki nilai risiko tinggi dan 2 sumber hazard yang memiliki nilai risiko sedang. Pengendalian dari semua bahaya kecelakaan kerja menurut tingkat risiko dilakukan dengan adanya kebijakan $\mathrm{K} 3$, pelatihan / penyuluhan K3, audit secara rutin dan terjadwal, melakukan pengadaan dengan terjadwal, pemeliharaan alat secara rutin, menggunakan APD, dan penerapan SOP.

\section{DAFTAR PUSTAKA}

Aryani, I. (2016). Risk Assessment pada Pekerjaan Bongkar Muat Kayu Log (Studi di Pelabuhan Dalam Tanjung Emas Semarang). Fakultas Kesehatan Masyarakat,Universitas Muhammadiyah Semarang.

Kyokai, N. K. (2009). Risk assessment guidelines.

Prasetio, D. B., Aryani, I., \& Meikawati, W. (2016). Risk Assessment Pekerjaan Bongkar Muatdi Pelabuhan Nusantara Tanjung Emas Semarang. In The 4th Univesity Research Coloquium (pp. 504509). STIKES Muhammadiyah Pakijangan.

Ramli, S. (2010). Sistem Manajemen Keselamatan dan Kesehatan Kerja OHSAS 18001. Jakarta: Dian Rakyat.

Saedi, A. M., Thambirajah, J. J., \& Pariatamby, A. (2014). A HIRARC model for safety and risk evaluation at a hydroelectric power generation plant. Safety Science, 70, 308315.

Sanusi, S., Despriadi, A., \& Yusdinata, Z. (2017). Analisa Potensi Bahaya dan Risiko Kegiatan Bongkar Muat di Pelabuhan PT Sarana Citranusa Kabil Dengan Metode HIRARC. Jurnal Teknik Ibnu Sina JT-IBSI, 2(1), 119-125. 
Suma'mur, P. K. (2000). Keselamatan Kerja dan Pencegahan Kecelakaan. Jakarta: Gunung Agung.

Supriyadi, S., Nalhadi, A., \& Rizaal, A. (2015). Identifikasi Bahaya dan Penilaian Risiko K3 pada Tindakan Perawatan \& Perbaikan Menggunakan Metode HIRARC (Hazard Identification and Risk Assesment Risk Control) pada PT. X. In Prosiding Seminar Nasional Riset Terapan/ SENASSET (pp. 281-286).

Supriyadi, S., \& Ramdan, F. (2017). Hazard Identification and Risk Assessment In Boiler Division using Hazard Identification Risk Assessment and Risk Control (HIRARC). Journal of Industrial Hygiene and Occupational Health, 1(2), 161-177. 